\title{
An introduction to Smart City in the service of Urban Crisis Management
}

\author{
Mahdi Shakibamanesh ${ }^{1 *}$
}

1 Urban Planning, Faculty of Architecture and Urban Planning, Shahid Beheshti University, Tehran, Iran; m.shakibamanesh@mail.sbu.ac.ir

\begin{abstract}
Wide range of urban issues whether human sources or natural disasters have given rise to a crisis in contemporary cities. This manuscript aims to introduce "smart crisis management ", to academic readers who are not familiar with this approach through the narrative review method and briefly present basic terms and definitions, the most recent paradigm: "digital twins" and finally represent three global best spatial applicants of smart city management in the era of crisis management. There are several criticisms discussed which could solve by Transformation to a more localized demand-oriented and more user-friendly applicant of smart city approach.
\end{abstract}

Keywords: Sustainable development, Smart City, Urban crisis management, Urban Planning

\section{Introduction}

Wide range of urban issues whether human sources or natural disasters have given rise to a crisis in contemporary cities. Also, the lack of coherent and immediate planning and smart management has caused lots of physical and non-physical damages to cities. This article aims to introduce basic concepts about the "smart crisis management view" and how do smart cities could help us to manage urban crises in a better way.

The Sustainable City is a city that moves forward in six characteristics: smart economy, smart mobility, smart environment, smart people, smart life, and smart governance, based on a combination of "smart" assets and activities that determine and act independently and inform citizens. [1] (p. 2).

\subsection{Basic terms and definitions}

A bunch of definitions related to the smart city in terms of technology-based view, social and human capital, or a combination of both are quoted below.

- Smart city is defined as a city in which ICT is merged with traditional infrastructures, coordinated and integrated using new digital technologies. [2] (p. 1).

Publisher's Note: UPCT and Sciforum stays neutral with regard to jurisdictional claims in published maps and institutional affiliations.

Copyright: () 2022 by the authors. Submitted for possible open access publication under the terms and conditions of the Creative Commons Attribution (CC BY) license (https://creativecommons.org/license s/by/4.0/).
Smart Cities as territories with high capacity for learning and innovation, which is built on the creativity of their population, institutions of knowledge creation, and their digital infrastructure for communication and knowledge management [3] (p. 1).

- Smarter city is connecting the physical infrastructure, the IT infrastructure, the social infrastructure, and the business infrastructure to leverage the collective intelligence of the city [4] (p. 1).

To put it in a nutshell, the smart city consists of four layers. (1) Sensor layer (i.e., wireless sensor nodes, such as RFID tags, RFID Readers, cameras, GPS, Qr code tags and readers), (2) Network layer (i.e., telecommunication network, TV network, Internet, broad, power grid, private networks), (3) Platform layer (i.e., service support platform, network management platform, information processing platform, information security platform) and (4) Application layer (i.e., smart healthcare, smart transportation, smart governance and smart crisis management). [5] (pp. 5-6). 


\section{Digital Twin City Paradigm}

The term "digital twins" can generally be defined as the creation of a dynamic virtual representation of a physical system, with connectivity and analytics capabilities using the Internet of Things. Specifically, about urban crisis management, a digital twin city updated by sensor-based instantaneous data can better understand cities and support decision-making. For example, a gas leak in a 3D Subject-oriented model is simulated with real data to identify potentially damaged areas and inform city dwellers in those areas of escape routes [6] (pp. 2-4).

The integration of ICT and Artificial intelligence (AI) adopted from different disciplines into the digital twin requires four components in the case of the crisis-stricken digital twin city. (1) Multi-data sensing for data collection, (2) data integration and analysis (3) multi-actor game-theoretic decision making, and (4) dynamic network analysis.

The first component focuses on AI technologies for collecting spatial data from multiple sources in a disaster which are usually Data-Starved due to limitations. Advances in AI have provided opportunities to address this challenge and to collect, store and analyze a variety of data, in particular through, remote sensing, social sensing, and the provision of public resources through remote sensing, social sensing, and crowdsourcing technologies are discussed as important elements of the Digital Twin for near real-time gathering and analysis of disaster and crisis situations.

The second component of a digital twin is related to the application of AI in the integration of heterogeneous data in order to draw the important insights needed by respondents and relief agents. For example, social media posts, volunteer and crowdsourced data, aerial photos, maps, reports, and news articles, and AI solutions (such as knowledge graphs and network embedding) to achieve machine learning on these data to inform disaster management and relief actions.

The third component includes a Serious Game Learning Environment to enable multi-actor decision making and networked coordination via AI for improving disaster response training and network-centric coordination based on approaches for multi-actor gaming scenarios.

The fourth component involves dynamic network analysis, considering the interactions among different types of networks, such as actors and information networks (for example, who coordinates with whom, who performs what tasks, and who What information is needed). To evaluate the performance of disaster management and humanitarian action in this component, we discuss the use of AI to investigate lost links in the network and record time information to improve the efficiency of disaster management efforts. [7] (pp. 1-7).

In another similar expression, in fact, (a) the real city data is collected through sensors or interactive data of users (b) and then entered into a computer and digital model (c) after modeling the complication (d) and completion $3 \mathrm{~d}$ model of buildings. (e) computer-simulated virtual environment (f) and finally make it available to various actors and urban decision-makers [6] (p. 2).

Also, there are several standards prepared in relation to Digital Twins technological components by the European Union, 2020 which is reflected in the table below.

Table 1. Relevant standardization activities for Digital Twins [8] (p. 13).

\begin{tabular}{cc}
\hline Topic & Relevant standardization support Technologies \\
\hline Support Technologies & IEEE 1516, SISO \\
\hline Simulation & Iso/IEC JTC 1/SC31 \\
\hline "Identification and & ISO/IEC JTC1/AG 13, Iso/IEC JTC1/Sc24, IEE P2048, Khronos Group \\
\hline Sensing" & IEC SC3D, ISO/TC 184/SC 4 \\
\hline AR/VR & ISO/IEC JTC1 SC 41 \\
\hline Product properties & ISO/IEC JTC1 SC 42 \\
\hline IoT & ISO/IEC JTC1 SC 47 \\
\hline
\end{tabular}




\section{Global sample practices in Smart Urban Crisis Management}

1

\subsection{Helsinki, Finland}

Helsinki, Finland has a long history of 3D modeling dating back to the mid-1980s. The city launched $\mathrm{a} € 1$ million initiative to produce a three-dimensional representation of the entire city, which was completed as part of a three-year project in 2017. This model now provides open data for public participation, research encouragement, and commercial development [9] (pp. 2-4).

This model consists of two types of modules: main module and add-on modules. main module Includes basic concepts and components such as land use, buildings, bridges, tunnels, traffic, water areas and heritage sites, vegetation, urban furniture, and other urban objects. Furthermore, Add-on modules enable the ability to add new subject classes such as energy information to buildings or climate analysis such as radiation and wind flow analysis to forecasting building vulnerability analysis in case of fire for instance. Finally, one of the most important strengths of this project and modeling is the ability to provide services and facilities for ordinary to professional users in the mobile application platform which is highly user friendly [10] (p. 35).

\subsection{Tokyo, Japan}

The use of national and international systems (data fusion) and rapid response teams (RRTs) has made Japan one of the most developed countries in this field. An appropriate response to the March 2011 earthquake and tsunami of Tohoku, Japan was one of the most successful experiences in the operation of smart urban crises management. In this case, Pwaves were detected by Japan's deep-sea monitoring systems at 2:46:48 p.m. (9 Richter) and issued a special warning (J-Alert). The S-waves arrived at exactly 14:47:17, and Japan had practically 21 seconds to prepare for the main quake. The Japan Meteorological Agency began performing a series of actions in a short period that were virtually impossible without smart systems. these actions are listed below [11] (pp. 1-5).

- Send SMS alert by three mobile operators in five languages

- Announcement from the official news agency of Japan (NHK)

- Begin the process of shutting down nuclear reactors

- Tokyo Electricity Company starts prioritizing electricity distribution

- Stop warning to Shinkansen high-speed trains

- Stop medical surgeries

- Cut off the gas flow

- Change of destination 86 flights

- Closing of runways at Hana Da and Narita airports

\subsection{Jakarta, Indonesia}

Due to the special location of Jakarta in Indonesia and its proximity to the ocean, witnessing floods and serious damages to the city's infrastructure and buildings each year. The Coastal Megacity Crisis Management Project was developed as a pilot project in Jakarta, in collaboration with the University of Wollongong, Australia, and the DKI (Jakarta Regional Disaster Management Agency), the output of which was the PetaJakarta.org project. This platform has been developed by using interactive data collection and with the help of social networks and citizens' shared posts, to request, collect, sorting and map floods in the city. Instant data collection and social-crowd data through popular social networks in Indonesia such as Twitter, Qlue, and Detik, and connection to the above system have been able to provide information to aid agencies and capabilities such as spatial prioritization. Predictability in similar situations in the coming years (based on three-year data interruption) and sharing crises with people while respecting the privacy of individuals is one of the advantages of this system [12] (pp. 1-9).
2

3 


\section{Conclusion}

A group of experts has criticized the smart city as a technocratic, corporate-led tool for managing cities. On the contrary, some believe that smart approaches are the basis for more democratic management practices in cities which are inevitable due to intellectual and financial resource distribution among various private and public actors. Other critics questioned how ordinary people participate according to their different desires and abilities and emphasized the fact that many people may not be able to use such technologies. However, it seems that in recent years, companies have increasingly focused on making more user-friendly technologies on an accessible platform such as smartphones. Some have argued for information reductionism and disregarding place-based context and knowledge. although it seems this objection has been fixed in recent approaches based on artificial intelligence and a higher level of social inclusion. The most important criticism debates the fact that many of these approaches in practice and local applications have been more under the pressure of technology than the real needs of cities and more under the pull of demand. Certainly, different cities are dealing with different challenges, actors, or even potentials so smartness must be formed by need and endogenously to be sustainable.

Finally, all the goals achieved if two conditions are met: first, attention to the local demographic, economic and ecological needs of each city and the relationship with different social and cultural contexts, and secondly, the accessibility of these technologies to the public and usability to maximize the role of communities in more democratic processes rather than technocratic ways to pave the way for sustainable development of future cities.

Funding: This research received no external funding.

Conflicts of Interest: The authors declare no conflict of interest.

\section{2} 3 4 5 6 https://doi.org/10.1016/j.compenvurbsys.2018.09.002. 